\title{
Heart Rate Variability Peculiarities in Adolescents with Psychopathology in the Educational Environment
}

\author{
Polina Mavrenkova, Natalia Pankova, Marina Lebedeva, Mikhail Karganov* \\ Institute of General Pathology and Pathophysiology, 8 Baltiyskaya St., Moscow 125315, Russia
}

Received September 28, 2021; Revised November 29, 2021; Accepted December 22, 2021

\section{Cite This Paper in the following Citation Styles}

(a): [1] Polina Mavrenkova, Natalia Pankova, Marina Lebedeva, Mikhail Karganov , "Heart Rate Variability Peculiarities in Adolescents with Psychopathology in the Educational Environment," Universal Journal of Public Health, Vol. 9, No. 6, pp. 445 - 453, 2021. DOI: 10.13189/ujph.2021.090612.

(b): Polina Mavrenkova, Natalia Pankova, Marina Lebedeva, Mikhail Karganov (2021). Heart Rate Variability Peculiarities in Adolescents with Psychopathology in the Educational Environment. Universal Journal of Public Health, 9(6), 445 - 453. DOI: 10.13189/ujph.2021.090612.

Copyright $\bigcirc 2021$ by authors, all rights reserved. Authors agree that this article remains permanently open access under the terms of the Creative Commons Attribution License 4.0 International License

\begin{abstract}
Under conditions of inclusive education, students with health limitations, in particular, children with neurological and mental disorders, have the opportunity to study at a general school. The goal of this study was to assess the possibility of using analysis of heart rate variability (HRV) as a relatively simple tool for evaluation of the adaptive resources in students with mental disorders and for early detection of dysfunctions in the neuroregulatory mechanisms in healthy students. We compared the spectral parameters of HRV and peripheral blood pressure in healthy adolescents $(\mathrm{n}=70)$ and adolescents with neuropsychiatric disorders $(n=58)$. Electrocardiogram was recorded for 2 minutes in a sitting posture, wearing a spirometric mask with voluntary breathing. Adolescents with mental disorders demonstrated a high total power of the HRV spectrum, an increased high-frequency power $(0.15-0.4 \mathrm{~Hz})$, a decreased low frequency / high-frequency ratio, and reduced total power and low frequency spectral power of systolic blood pressure variability. The revealed differences were observed mainly in males. The presented data demonstrate an increased vagal tone in adolescents with mental disabilities. Our findings support the idea that HRV can be used in schools to identify risk groups of vulnerability to mental disorders.
\end{abstract}

Keywords Schoolchildren Health, Health-Saving Activities, Adolescents, Mental Disorders, Heart Rate Variability

\section{Introduction}

The modern educational process is aimed at the development of creativity and the growth of the cognitive, psychological, physical, and social well-being of each student [1]. Inclusive education is an important trend in secondary schools [2 -4]. Within the framework of this concept, schools create conditions for education for different categories of students, including individuals with health limitations (HL), in particular, children with neurological and mental disorders. In Russia traditionally, these children were educated in special schools, which reduced the possibility of their socialization [3, 5]. Integrated learning implies that children with HL acquire knowledge according to their abilities under the same conditions as normally developing children in accordance with the state educational standards. However, it should be taken into account that even if the psychophysical development of a child with disabilities allows him attending mass educational institutions, he, due to developmental disability, still has special educational needs that should be met. This cohort of students requires constant medical, psychological, and pedagogical support.

Another problem the school is facing for many years is the deterioration of students' health due to environmental, genetic, family, and school factors [6 - 9]. Health status affects cognitive abilities, learning success, and, as a result, the future quality of life. Adolescence is a developmental stage that determines health in adulthood and health of future generations. Official statistics show increased general and primary morbidity and high rates of 
chronization of pathological processes in adolescents [10, 11]. In the structure of diseases of high school students, one of the leading places is occupied by mental disorders [1214]. This trend may be associated with a high overall academic load of high school students in combination with insufficient motor activity, reduced sleep duration, prolonged use of the computer and uncontrolled use of the Internet $[11,15]$. These factors in combination with adverse social and environmental impacts and biological causes (primarily, changes in the hormonal status) lead to overstrain and a decrease in adaptive capacities of adolescents, and then, to the formation of manifest health disorders: functional disorders, asthenia, exacerbation of chronic diseases, behavioral deviations. The negative impact of the school environment is $12 \%$ in primary school and $21 \%$ in the high school [10]. The situation is complicated by the fact that school risk factors affect students' health overseveral years and their negative effects become apparent after certain time. However, initial symptoms of violations of physical and mental health do not attract attention of teachers and parents until they transform into a manifest pathology. In this context, the most important task in the organization of the educational process in the school is creation of the health-preserving environment, i.e. conditions ensuring acquisition of knowledge and skills and preserving the psychophysical status of healthy individuals. For solving this problem, timely detection of symptoms of reduced adaptive capabilities of the body and implementation of scientifically substantiated preventive measures are required to maintainthe optimal level of health in students. Heart rate variability (HRV) is a relatively simple and cost-effective method of monitoring characterized by good predictive potential.

The purpose of this study was to assess the possibility of using HRV parameters for evaluation of the adaptive resources of adolescent students with neuropsychiatric disorders and for early detection of dysfunctional changes in the regulatorymechanisms in healthy adolescents.

\section{Materials and Methods}

The research was carried out in the course of sanogenetic monitoring of schoolchildren in Moscow within the framework of the state program for the development of a technology for assessing population health based on the software and hardware complex of polysystemic studies. We examined 12 -17-year-old white adolescents of both sexes,students of regular and correctional schools (Table 1). The students of regular schools without mental or neurological disorders according to medical records formed the group "Healthy" $(\mathrm{H})$. The group "Health limitations" (HL) included adolescents from a correctional school with neuropsychiatric diagnoses according to ICD-10. At the time of testing, these adolescents were in remission. Inclusion criteria: all schoolchildren included in the study had no history of cardiovascular pathologies. Exclusion criteria for group "Healthy": mental or neurological disorders.

The study was conducted according to the guidelines of the Declaration of Helsinki, and approved by the Ethics Committee of Institute of General Pathology and Pathophysiology (Protocol No. 1 of 22.01.2019). Informed consent was obtained from all subjects and their legal representatives involved in the study.

Electrocardiogram (ECG) was recorded on a spiroarteriocardiorhythmograph (SACR; Intoks Company, St. Petersburg)in standard lead I. in the sitting position over 2 min after adaptation of the examinees to the experimental conditions wearing a spirometric mask, with voluntary breathing [16]. In parallel with ECG, peripheral blood pressure $(\mathrm{BP}, \mathrm{mm} \mathrm{Hg})$ in the digital artery was recorded by the Penaz method [17]. The R-R interval time series was manually checked for the presence of artifacts; spuriously detected or missed $\mathrm{R}$ waves were corrected by linear interpolation. Spectral analysis of HRV and BP variability (BPV) was performed using SACR algorithms. For short records $(2-5 \mathrm{~min})$, three main frequency ranges are commonly distinguished: very low frequency (VLF, $<0.04$ $\mathrm{Hz}$ ), low frequency (LF, $0.04-0.15 \mathrm{~Hz}$ ), and high frequency (HF, 0.15-0.4 Hz) (Heart rate variability, 1996). The following parameters were analyzed: the absolute total power spectral densities in the range of $0-40 \mathrm{~Hz}$ (TP) and the power spectral densities in each frequency range (msec2); relative spectral power of these frequency bands (HF\%, LF\%, VLF\%), normalized power LFn (LF / (TP VLF) and HFn (HF / (TP - VLF), LF / HF ratio. For evaluation of adaptation of the cardiovascular system to factors of the external and internal environment, the stress-index of regulatory systems (SI) was calculated based on geometric parameters of HRV (mode, mode amplitude, etc.) [18]. Under conditions of continuous BP measurement, the frequency method was used to determine spontaneous baroreflex sensitivity (BRS): the $\alpha$-index was defined as the square root of the ratio of the spectral powers of HRV and systolic BP (sBP) within a band of a LF frequency [19].

Table 1. Sex and age composition of the groups

\begin{tabular}{|c|c|c|c|c|c|c|c|c|}
\hline Group & \multicolumn{4}{|c|}{ "Healthy" } & \multicolumn{4}{|c|}{ "Health limited" } \\
\hline Sex & \multicolumn{2}{|c|}{ Males $(\mathrm{n}=38)$} & \multicolumn{2}{|c|}{ Females $(\mathrm{n}=32)$} & \multicolumn{2}{|c|}{ Males $(n=40)$} & \multicolumn{2}{|c|}{ Females $(\mathrm{n}=18)$} \\
\hline Age & $\begin{array}{l}12-15 \\
(\mathrm{n}=17)\end{array}$ & $\begin{array}{l}15-17.5 \\
(\mathrm{n}=21)\end{array}$ & $\begin{array}{l}12-15 \\
(\mathrm{n}=8)\end{array}$ & $\begin{array}{l}15-17.5 \\
(\mathrm{n}=24)\end{array}$ & $\begin{array}{l}12-15 \\
(\mathrm{n}=13)\end{array}$ & $\begin{array}{l}15-17.5 \\
(\mathrm{n}=27)\end{array}$ & $\begin{array}{l}12-15 \\
(\mathrm{n}=5)\end{array}$ & $\begin{array}{l}15-17.5 \\
(\mathrm{n}=13)\end{array}$ \\
\hline
\end{tabular}

Note: Age was estimated with an accuracy of a month. Codes of diagnoses: F06.68 ( $n=17)$, F06.78 $(n=3) ;$ F06.82 $(n=4)$, F06.36 $(n=1)$, F07.8 $(\mathrm{n}=8)$, F21.8(n=2); F29.6 ( $\mathrm{n}=2)$, F30.9 $(\mathrm{n}=2) ; \mathrm{F} 32.01(\mathrm{n}=2), \mathrm{F} 40.8(\mathrm{n}=1), \mathrm{F} 42.8(\mathrm{n}=1), \mathrm{F} 43.25(\mathrm{n}=1), \mathrm{F} 89(\mathrm{n}=7)$, F91.9 $(\mathrm{n}=1)$, F98.5 $(\mathrm{n}$ $=6)$. 
The results were processed statistically using "Statistica 7.0" software (StatSoft Inc., Tulsa, OK, USA). As preliminary testing did not allow accepting the hypothesis on normal distribution of experimental data and homogeneity of variances for each subgroup (with the exception of heart rate, HR), the nonparametric Kruskal-Wallis test followed by multiple comparisons according to Dunn's multiple comparisons test for unequal samples was used. The influence of mental illness (two levels: healthy and health limited), sex (two levels: male and female), and age (two levels: 11,5 - 15 years and $15-$ 17,5 years) on all parameters was tested using factorial ANOVAs after preliminary logarithmic transformation of the variables. One-way ANOVA was used for HR. The accepted significance level was 5\%. The data are presented as the median (Me) and the upper and lower quartiles (Q1 Q3).

\section{Results}

Analysis of HR, as well as logarithmic parameters of HRV and BPV in adolescents revealed the influence of the factor "health" on almost all indicators of HRV and on some parameters of systolic BPV (table 2). There was no statistically significant influence of the factors "sex" and "age" on the estimated indicators. However, the interaction of factors was revealed for some characteristics of HRV and BDP.

Detailed analysis of the HRV spectrum showed that in the group of HL adolescents, TP and the absolute, relative, and normalized values of HF were higher than in the group of $\mathrm{H}$ schoolchildren, and the calculated indicators LF / HF and SI ( $\mathrm{p}=0,050)$ were expectedly reduced (Table 3$)$. In the HL group, the values of SBP and $\mathrm{dBP}$ were higher than in the $\mathrm{H}$ control group, but remained within normal BP. The decrease in sTP and SLF was accompanied by an increase in the $\alpha$-index BRS.

Table 2. Influence of the factor "health" on the parameters of HRV and BPV: F(1, 120); $p$

\begin{tabular}{|c|c|c|c|c|c|c|c|c|c|c|c|c|}
\hline \multicolumn{10}{|c|}{ Heart rate variability } \\
\hline HR & TP & LFn & HFn & VLF & LF & HF & VLF\% & LF\% & HF\% & LF/HF & SI \\
\hline $\mathbf{4 . 4 7} ;$ & $\mathbf{7 . 8 9} ;$ & $\mathbf{1 1 . 8 2} ;$ & $\mathbf{5 . 9 4} ;$ & $0.001 ;$ & $1.62 ;$ & $\mathbf{1 4 . 8 5} ;$ & $\mathbf{7 . 8 2} ;$ & $\mathbf{5 . 0 7} ;$ & $\mathbf{9 . 5 3}$ & $\mathbf{9 . 4 3}$ & $\mathbf{4 . 3 3}$ \\
$\mathbf{0 . 0 3 6}$ & $\mathbf{0 . 0 0 6}$ & $\mathbf{0 . 0 0 1}$ & $\mathbf{0 . 0 1 6}$ & 0.971 & 0.205 & $\mathbf{0 . 0 0 1}$ & $\mathbf{0 . 0 0 6}$ & $\mathbf{0 . 0 2 6}$ & $\mathbf{0 . 0 0 2}$ & $\mathbf{0 . 0 0 3}$ & $\mathbf{0 . 0 4 0}$ \\
\hline \multicolumn{10}{|c|}{ Blood pressure variability } \\
\hline sBP & dBP & sTP & sLF & sHF & sLF\% & sHF\% & dTP & dLF & dHF & dLF\% & dHF\% & $\alpha$-index BRS \\
\hline $0.11 ;$ & $3.31 ;$ & $1.83 ;$ & $9.90 ;$ & $0.02 ;$ & 10.95 & $3.27 ;$ & $0.20 ;$ & $1.15 ;$ & $0.55 ;$ & $1.87 ;$ & $2.26 ;$ & $12.9 ;$ \\
0.744 & 0.076 & 0.178 & 0.002 & 0.900 & 0.001 & 0.073 & 0.658 & 0.286 & 0.460 & 0.174 & 0.135 & 0.0004 \\
\hline
\end{tabular}

Note: TP - total power; sBP -systolic blood pressure; dBP - diastolic blood pressure; $\alpha$-index BRS - baroreflex sensitivity; SI - stress-index

Table 3. Characteristics of heart rate variability and peripheral blood pressure variability in adolescents from general and correctional schools

\begin{tabular}{|c|c|c|c|c|c|c|c|c|c|}
\hline & \multicolumn{9}{|c|}{ Heart rate variability } \\
\hline & TP & VLF & LF & HF & VLF\% & LF\% & HF\% & LFn & HFn \\
\hline $\mathrm{H}$ & $\begin{array}{c}1853.23 \\
{[1000.27} \\
3262.53]\end{array}$ & $\begin{array}{c}471.32 \\
{[148.36} \\
739.04]\end{array}$ & $\begin{array}{c}583.03 \\
{[411.21 ;} \\
1303.26]\end{array}$ & $\begin{array}{c}491.93 \\
{[278.44 ;} \\
993.67]\end{array}$ & $\begin{array}{c}19.95 \\
{[11.37 ;} \\
41.06]\end{array}$ & $\begin{array}{c}40.06 \\
{[29.42 ;} \\
54.07]\end{array}$ & $\begin{array}{c}29.72 \\
{[17.13 ;} \\
44.20]\end{array}$ & $\begin{array}{c}0.58 \\
{[0.42 ;} \\
0.72]\end{array}$ & $\begin{array}{c}0.42 \\
{[0.28 ;} \\
0.58]\end{array}$ \\
\hline $\mathrm{HL}$ & $\begin{array}{l}2901.50 * \\
{[1693.03 ;} \\
5778.13] \\
\end{array}$ & $\begin{array}{l}466.10 \\
{[208.53} \\
670.68] \\
\end{array}$ & $\begin{array}{c}767.98+ \\
{[497.23} \\
1938.95]\end{array}$ & $\begin{array}{l}1059.56^{*} \\
{[500.88 ;} \\
2668.19]\end{array}$ & $\begin{array}{l}13.97 * \\
{[6.03 ;} \\
28.68]\end{array}$ & $\begin{array}{c}33.48 \\
{[23.11} \\
50.87] \\
\end{array}$ & $\begin{array}{l}42.98 * \\
{[26.17 ;} \\
67.28] \\
\end{array}$ & $\begin{array}{c}0.50^{*} \\
{[0.26 ;} \\
0.66]\end{array}$ & $\begin{array}{c}0.50 * \\
{[0.34 ;} \\
0.74]\end{array}$ \\
\hline \multicolumn{7}{|c|}{ Peripheral blood pressure } & \multicolumn{3}{|c|}{ Indices } \\
\hline & sBP & dBP & TPs & VLFs & LFs & HFs & $\alpha$ & LF/HF & SI \\
\hline $\mathrm{H}$ & $\begin{array}{c}107.62 \\
{[100.90} \\
118.90]\end{array}$ & $\begin{array}{r}67.36 \\
{[59.60 ;} \\
79.11] \\
\end{array}$ & $\begin{array}{r}21.06 \\
{[12.40 ;} \\
29.71] \\
\end{array}$ & $\begin{array}{c}7.30 \\
{[3.04 ;} \\
13.35]\end{array}$ & $\begin{array}{c}6.75 \\
{[3.86 ;} \\
12.22] \\
\end{array}$ & $\begin{array}{c}3.63 \\
{[1.70 ;} \\
6.29] \\
\end{array}$ & $\begin{array}{l}10.40 \\
{[7.6 ;} \\
14.7]\end{array}$ & $\begin{array}{r}2.36 \\
{[0.73 ;} \\
2.54]\end{array}$ & $\begin{array}{r}162.86 \\
{[104.35} \\
312.42] \\
\end{array}$ \\
\hline $\mathrm{HL}$ & $\begin{array}{c}119.27 * \\
{[107.90} \\
125.80]\end{array}$ & $\begin{array}{l}77.74 * \\
{[61.72 ;} \\
83.44]\end{array}$ & $\begin{array}{l}13.93 * \\
{[8.89 ;} \\
21.38]\end{array}$ & $\begin{array}{l}3.86+ \\
{[1.82 ;} \\
10.95]\end{array}$ & $\begin{array}{c}3.14 * \\
{[1.49 ;} \\
6.73]\end{array}$ & $\begin{array}{l}3.25 \\
{[1.95 ;} \\
6.85]\end{array}$ & $\begin{array}{l}17.65 * \\
{[12.3 ;} \\
25.00]\end{array}$ & $\begin{array}{c}1.32 * \\
{[0.34 ;} \\
1.98]\end{array}$ & $\begin{array}{l}256.96 \\
{[115.94} \\
428.77]\end{array}$ \\
\hline
\end{tabular}

Note: TP - total power; sBP -systolic blood pressure; dBP - diastolic blood pressure; $\alpha$-index - baroreflex sensitivity; $\mathrm{SI}-\mathrm{stress-index;}{ }^{*} \mathrm{p}<0.05$. $+\mathrm{p}<0.09$ incomparison with the healthy adolescents 


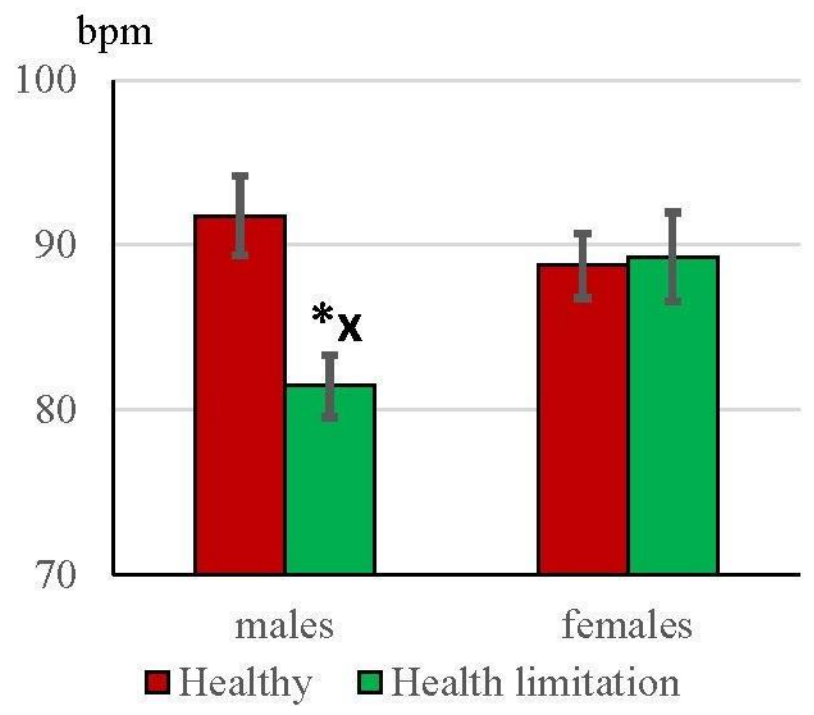

Figure 1. Heart rate in healthy males and females and in adolescents with mental disorders
Since the interaction of factors was found for some characteristics of $\mathrm{HRV}$ and $\mathrm{BPV}$, for further analysis by nonparametric methods, we divided the groups by sex: " $\mathrm{H}$ males", "H females", "HL males", "HL females". One-way ANOVA revealed differences in HR between these groups: $\mathrm{F}(3,125)=5.084, \mathrm{p}=0.002$. Post hoc comparison by Newman-Keuls test showed that in the group of HL males, $\mathrm{HR}$ was lower than in $\mathrm{H}$ males and HL females (Figure 1).

Spectral analysis of HRV showed that TP in HL adolescents of both sexes was slightly higher than in $\mathrm{H}$ schoolchildren, but the differences did not reach statistical significance (table 4). The absolute power of HF range was elevated significantly in boys and at the level of a trend - in girls with mental disorders in comparison with healthy adolescents. As a result, the LF / HF ratio in HL males tended to decrease.

Groups: "Healthy" - adolescents from general school; "Health limitation" - adolescents with psychiatric diagnoses from correctional school. $* \mathrm{p}=0.008$ in comparison with $\mathrm{H}$ males; $\mathrm{Xp}=0.042$ in comparison with HL females

Table 4. Characteristics of HRV and peripheral BPV in adolescents from general and correctional school

\begin{tabular}{|c|c|c|c|c|c|}
\hline Group & \multicolumn{2}{|c|}{ Healthy } & \multicolumn{2}{|c|}{ Health limitations } & \multirow{2}{*}{$\begin{array}{c}\text { Kruskal-Wallis test } \\
\mathrm{H}(3 . \mathrm{N}=128)\end{array}$} \\
\hline Sex & males & females & males & females & \\
\hline ТP & $\begin{array}{c}2117.88 \\
{[974.59 ; 3414.17]} \\
\end{array}$ & $\begin{array}{c}1657.14 \\
{[1018.34 ; 3255.35]}\end{array}$ & $\begin{array}{c}2871.68 * \mathrm{t}[1713.94 \\
5636.51]\end{array}$ & $\begin{array}{c}2903.90 \\
{[1531.82 ; 5778.13]}\end{array}$ & $\begin{array}{c}9.705 \\
p=0.021\end{array}$ \\
\hline VLF & $\begin{array}{c}248.14 \\
{[101.64 ; 641.27]}\end{array}$ & $\begin{array}{c}569.06 \\
{[179.12 ; 981.45]}\end{array}$ & $\begin{array}{c}561.86 \\
{[262.35 ; 926.73]}\end{array}$ & $\begin{array}{c}211.87 \\
{[119.35 ; 608.36]}\end{array}$ & $\begin{array}{c}8.927 \\
\mathbf{p}=\mathbf{0 . 0 3 0}\end{array}$ \\
\hline LF & $\begin{array}{c}707.19 \\
{[433.27 ; 1781.52]}\end{array}$ & $\begin{array}{c}540.30 \\
{[394.38 ; 984.68]}\end{array}$ & $\begin{array}{c}741.34 \\
{[509.85 ; 1834.22]}\end{array}$ & $\begin{array}{c}957.85 \\
{[461.17 ; 2318.08]}\end{array}$ & $\begin{array}{c}4.507 \\
p=0.212\end{array}$ \\
\hline $\mathrm{HF}$ & $\begin{array}{c}495.49 \\
{[281.48 ; 1146.00]}\end{array}$ & $\begin{array}{c}488.36 \\
{[239.82 ; 764.04]}\end{array}$ & $\begin{array}{c}1059.56 * \\
{[517.43 ; 2586.88]}\end{array}$ & $\begin{array}{c}1113.41 * \mathrm{t} \\
{[456.52 ; 2928.4]}\end{array}$ & $\begin{array}{c}14.708 \\
p=0.002\end{array}$ \\
\hline $\mathrm{LF} / \mathrm{HF}$ & $\begin{array}{c}1.46 \\
{[0.82 ; 4.29]} \\
\end{array}$ & $\begin{array}{c}1.22 \\
{[0.71 ; 2.32]}\end{array}$ & $1.15 * \mathrm{t}[0.34 ; 2.06]$ & $\begin{array}{c}0.85 \\
{[0.39 ; 1.83]}\end{array}$ & $\begin{array}{c}8.727 \\
\mathbf{p}=\mathbf{0 . 0 3 3}\end{array}$ \\
\hline SI & $\begin{array}{c}313.48 \\
{[134.01 ; 489.43]}\end{array}$ & $\begin{array}{c}224.34 \\
{[94.59 ; 377.16]}\end{array}$ & $\begin{array}{c}153.08 \\
{[96.33 ; 356.74]}\end{array}$ & $\begin{array}{c}164.51 \\
{[113.58 ; 239.82]}\end{array}$ & $\begin{array}{c}4.992 \\
p=0.172\end{array}$ \\
\hline sBP & $\begin{array}{c}106.63 \\
{[101.33 ; 118.9]}\end{array}$ & $\begin{array}{c}107.64 \\
{[98.17 ; 117.80]}\end{array}$ & $\begin{array}{c}121.23 *[109.93 ; \\
127.47]\end{array}$ & $\begin{array}{c}115.21 \\
{[100.71 ; 121.89]}\end{array}$ & $\begin{array}{c}10.828 \\
p=0.013\end{array}$ \\
\hline $\mathrm{dBP}$ & $\begin{array}{c}66.95 \\
{[58.92 ; 79.10]}\end{array}$ & $\begin{array}{c}67.76 \\
{[59.60 ; 81.46]}\end{array}$ & $78.03 *[64.91 ; 86.56]$ & $\begin{array}{c}70.89 \\
{[61.12 ; 80.48]}\end{array}$ & $\begin{array}{c}8.917 \\
p=0.030\end{array}$ \\
\hline$\alpha$-index & $\begin{array}{c}10.3 \\
{[6.6 ; 14.7]}\end{array}$ & $\begin{array}{c}10.5 \\
{[7.6 ; 14.7]}\end{array}$ & $\begin{array}{c}19.4 * \\
{[13.55 ; 27.75]}\end{array}$ & $\begin{array}{c}14.85 \\
{[7.8 ; 20.40]}\end{array}$ & $\begin{array}{c}27.25181 \\
p<0.0001\end{array}$ \\
\hline
\end{tabular}

Note: designations as in table $3 .{ }^{*} \mathrm{p}<0.05$ (dark gray). $(* t) \mathrm{p}<0.08$ (light gray) in comparison with the corresponding subgroups of healthy adolescents 


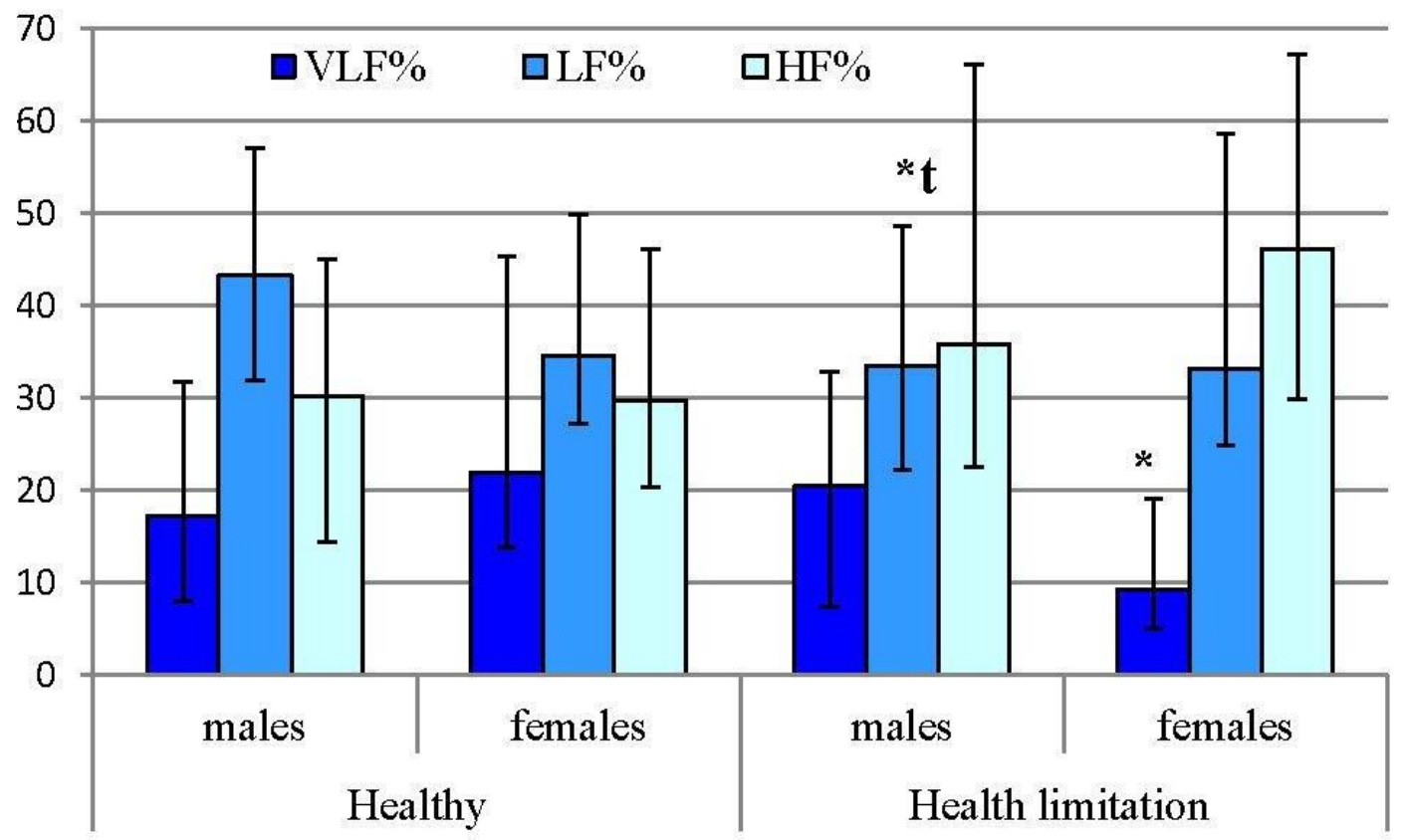

Figure 2. The contribution of standard frequency ranges into HRV in healthy males and females and adolescents with mental disorders.

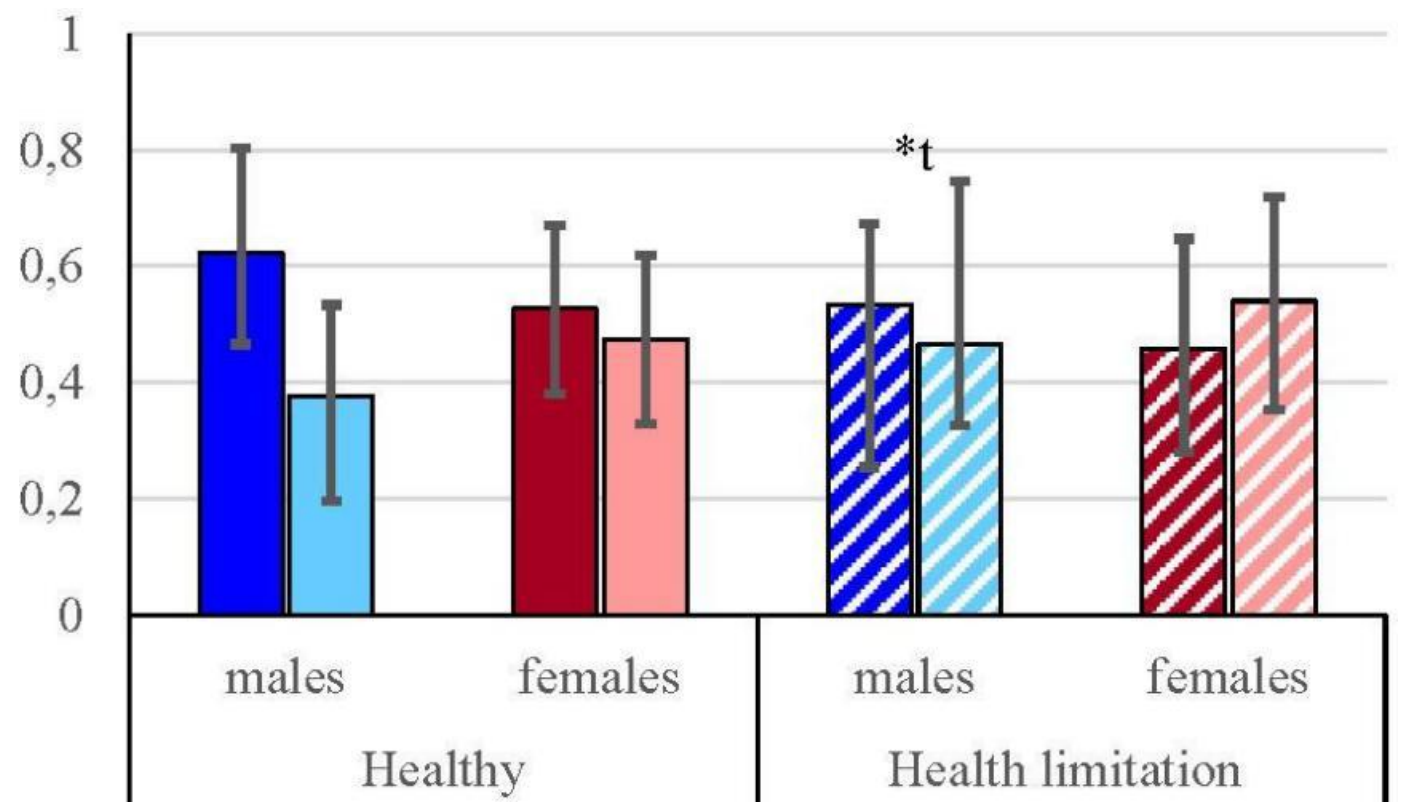

Figure 3. The contribution of standard frequency ranges into HRV in healthy males and females and adolescents with mental disorders.

The relative power of the LF and HF ranges did not differ significantly between the subgroups; VLF\% in HL females was decreased in comparison with that in the control subgroup (Figure 2).

Kruskal-Wallis test: VLF\% H $(3, \mathrm{~N}=128)=10.117 \mathrm{p}=$ $0.017 ; \mathrm{LF} \% \mathrm{H}(3, \mathrm{~N}=128)=6.127 \mathrm{p}=0.106 ; \mathrm{HF} \% \mathrm{H}(3$, $\mathrm{N}=128)=9.775 \mathrm{p}=0.021 ;$ post-hoc analysis $* \mathrm{p}<0.05$

Analysis of LFn and HFn showed that HL males had a pronounced tendency to decrease LFn and increase HFn compared with $\mathrm{H}$ males (Figure 3).
In HL males (but not in HL females), peripheral sBP and barorefex sensitivity were higher than in $\mathrm{H}$ males (table 4). In HL males, sTP of BPV and the absolute and relative power spectral density of the LFs band were significantly reduced incomparison with control subgroup (Figure 4)

Kruskal-Wallis test: VLF\% H $(3, \mathrm{~N}=128)=10.117 \mathrm{p}=$ 0.017 ; LF\% H (3, N= 128) $=6.127 \mathrm{p}=0.106 ; \mathrm{HF} \% \mathrm{H}(3$, $\mathrm{N}=128)=9.775 \mathrm{p}=0.021 ;$ post-hoc analysis $* \mathrm{p}<0.05$ 


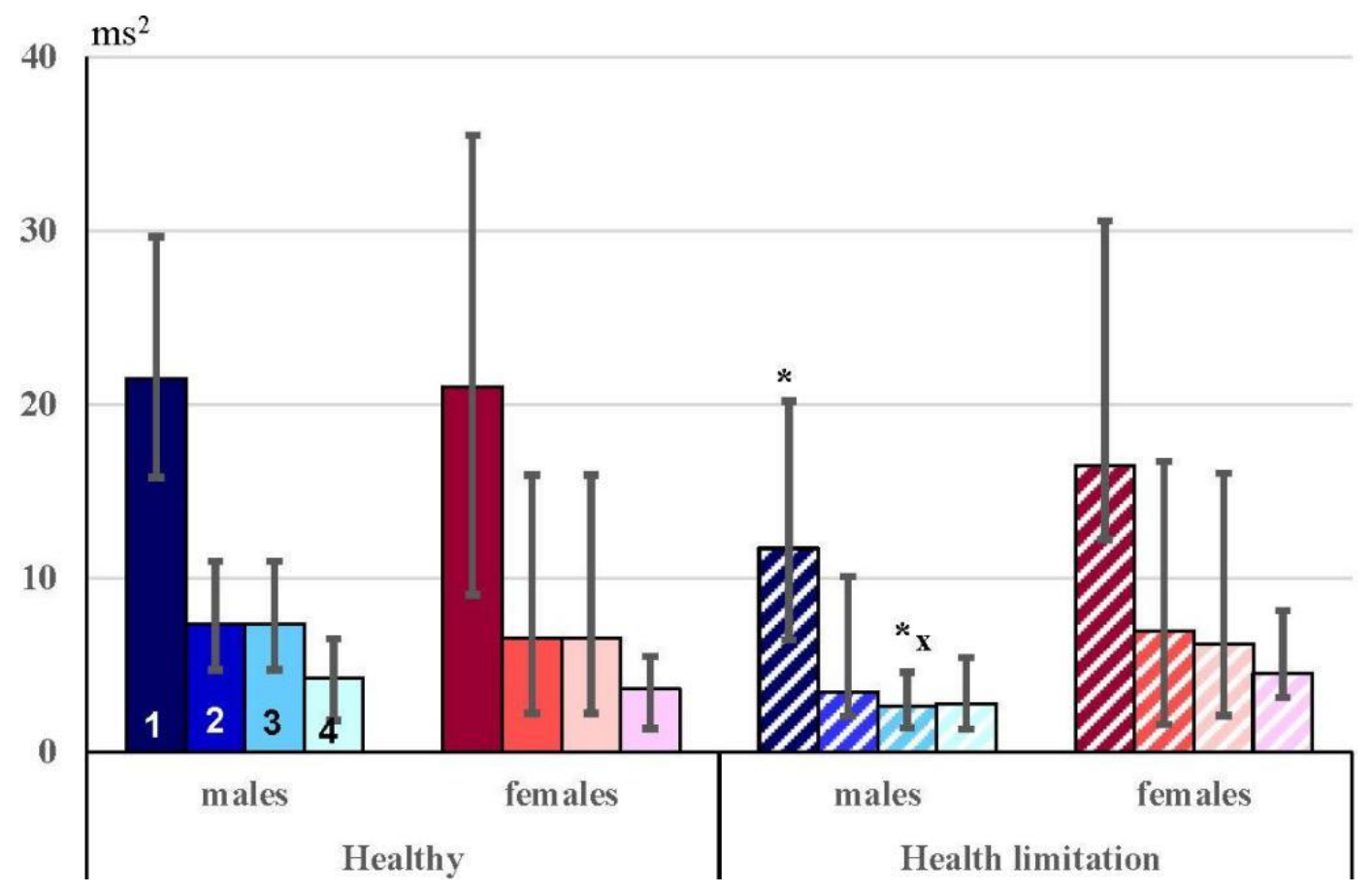

Figure 4. Spectral parameters of peripheral systolic blood pressure in healthy adolescents and adolescents with mental disorders

In each subgroup: the first column is the total power spectral density (TPs) $\mathrm{H}(3, \mathrm{~N}=128)=12.193 \mathrm{p}=0.007$; the second, third and fourth columns are the power spectral densities in standard frequency ranges: $\operatorname{sVLF~H}(3, \mathrm{~N}=128)$ $=4.805 \mathrm{p}=0.187 ; \operatorname{sLF} \mathrm{H}(3, \mathrm{~N}=128)=23.154 \mathrm{p}<0.0001$; $\operatorname{sHF} \mathrm{H}(3, \mathrm{~N}=128)=5,121 \mathrm{p}=0.163$. Post-hoc analysis $* \mathrm{p}$ $<0,001$ in comparison with $\mathrm{H}$ males, $\mathrm{xp}=0.088$ in comparison with HL females.

\section{Discussion}

We have previously demonstrated that the recording of HRV in a spirometric mask simulates the state of mild mixed hypoxia and hypercapnia and can be considered as light functional stress test [20]. Under these conditions, male adolescents with mental disorders showed lower HR and higher BP compared to healthy controls. Differences in HRV were revealed only at the tendency level. But when we analyzed HRV without taking into account sex, the power spectral densities in HF-frequency range in adolescents with mental disorders were higher than in the control group, and the LF / HF ratio was reduced. Frequency analysis of BPV showed a decrease in the TPs and LFs and an increase in the BRS in HL males.

The functions of the heart and other organs are regulated at different levels: humoral effects, influence of the autonomic nervous system (ANS) circuit, and control from suprasegmental structures of the central nervous system (primarily, the hypothalamus and brain cortex). The interaction of the sympathetic and parasympathetic divisions of the ANS, central nervous mechanisms, and hormonal influences ensures adaptation to changing environmental conditions and maintenance of homeostasis. The changes in the regulatory systems precede the hemodynamic, metabolic, and energy disorders and, therefore, represent the earliest predictive signs of health problems. Registration of myocardial contractions allows assessing the influence of regulatory systems of the body on the function of the cardiovascular system, because registration of activity of other internal organs is difficult. Thus, the rhythm of cardiac contractions can serve as an indicator of deviations of regulatory systems from optimal functioning.

HR is an available indicator of autonomic imbalance. There is evidence that increased or decreased HR at rest can be associated with the development of mental disorders. For instance, one longitudinal study showed that men with high HR in adolescence more often develop obsessive-compulsive disorders, schizophrenia, and anxiety disorders in adulthood; on the contrary, reduced HR was associated with the risk of developing addictive and aggressive behavior [21]. The authors believe that the differences in the functioning of ANS that mediate HR can precede the development of mental disorders or represent their early markers.

HRV is the variations in the time interval between consecutive heartbeats over a certain period, the duration of which is determined by the study objectives [22, 23]. HRV is used as an informative non-invasive method for assessing functional state of the body under conditions of its adaptation to physical and mental loads. Analysis of HRV within the framework of health-protecting technologies is of great prognostic and diagnostic value in various somatic diseases (cardiovascular, respiratory, endocrine system pathologies) [24], and for evaluation of 
the "quality of health" of a healthy person, physical fitness, and resistance to psycho-emotional stress in participants of educational process (students, teachers) [25].

Currently, HRV is proposed to be used as a transdiagnostic neurobiological marker in mental disorders [26]. In this regard, extensive studies of HRV are conducted in patients with psychiatric diagnoses. Most authors report a decrease in HRV at rest and / or in stressful situations in patients with depression, anxiety, schizophrenia, and autism spectrum disorders [27 - 29]. Such changes in HRV are often associated with a decrease in the HF band of the spectrum, which reflects the parasympathetic activity of the ANS. In patients with mental disorders autonomic balance is shifted towards the increase in sympathetic tone [30]. But there are evidences of an increase in HRV in some emotional and behavioral disorders. Among patients with affective disorder, the power of the HF component of HRV at rest may be higher or lower than in healthy subjects, which apparently reflects the heterogeneity of the endophenotypes of depression [31] In a longitudinal cohort study in healthy people, it was shown that parasympathetic predominance may precede the onset of depression in older adults [32]. An increased power of the HF spectrum band has been found in patients with generalized anxiety disorder at rest [33]. These results were obtained in adults, often during physical or emotional activity.

In our study, adolescents from the correctional school during ECG recording while wearing a spirometric mask demonstrated higher activity of the parasympathetic ANS compared with controls. This unexpected result may be a task-related response to the light hypoxic load. In the literature, a decrease in parasympathetic tone and a decrease in HRV are more often discussed in children and adolescents with mental illness at rest and during physical, mental or emotional stress. However, children with attention-deficit/hyperactivity disorder had a parasympathetic dominance of the autonomic balance that was confirmed by higher overall HRV and lower HR in comparison with control subjects [34]. Anorexia nervosa in young females was accompanied by bradycardia, increase in TP and HF spectral power, decrease in LF power and $\mathrm{LF} / \mathrm{HF}$ ratio, which indicated prevalence of the parasympathetic over sympathetic activity $[35,36]$. Some authors note a paradoxical increase in vagal tone during light exercise tests. Adolescents with autism spectrum disorders demonstrated either suppression or activation of the parasympathetic ANS during a simple arithmetic task [37].

Function of ANS may be evaluated more reliably by analyzing BPV and BRS together with HRV. The power spectrum of BPV has been reported to be a useful marker of sympathetic nervous function [38]. In addition, BRS is known to reflect the combined effect of sympathetic and parasympathetic modulation of HR controlled by arterial baroreceptors [39]. Revealed that BRS was higher, and LF power of BPV was lower in anorexia nervosa patients in comparison with controls [36]. It should be noted that spectral analysis of BPV at short-term intervals was addressed in only few studies [40, 41]. Further studies in this field are required for correct interpretation of the obtained results.

Our research has a number of limitations. The duration of HRV measurements was rather short, which might have an impact on reliability of the measurement. Although some ultra-short (less than $5 \mathrm{~min}$ ) HRV features can be considered as valid surrogates of HRV characteristics for standard recording [23, 44, 45], it is recommended to take longer measurements when possible. Another limitation is that the group "Health limitation" included adolescents with various mental disorders. It is assumed that the HRV shifts can be specific for different nosological groups of mental disorders $[42,46]$. In our study, we were not able to determine the characteristics of HRV for certain diseases, and the revealed differences from control reflect the changes common for psychopathology. Let us also note an incomplete description of the mental and somatic status of examined adolescents and medications taken by children with health limitations.

In addition, the study did not include any functional tests, although differences in HRV reactivity for mental disorders were shown [33]. Future studies should implement control conditions that account for these problems.

\section{Conclusions}

Reduced stress tolerance affects mental well-being and may be associated with a high risk of mental disorders. In general schools, assessment of stress tolerance is based on the results of psychological tests and subjective reports. In this situation, introduction of objective biological/physiological markers of stress resistance into the educational environment is required. A promising approach is the use of HRV as a biomarker of stability of mental health. High activity of the parasympathetic nervous system that provides a high-frequency component of HRV spectral power is associated with cognitive resistance to the problems related to competitive activity and self-control, as well as with appropriate emotional and humoral regulation during psychosocial interaction [43]. Our findings support the idea that HRV can be used in schools to identify risk groups by vulnerability to mental disorders. However, for correct application of this method and correct interpretation of the results, an extensive database on HRV reactivity and other parameters [47] in healthy schoolchildren and children with health limitations is required. Research in this field [48] should be continued with the use of modern individual devices for recording heart rate, behaviors, and patient reported outcomes describing emotions during daily life. 


\section{REFERENCES}

[1] Education Policy Outlook 2019: Working Together to Help Students Achieve their Potential. OECD, 2019 Annual ISSN: 27076725 online available from https://doi.org/10.1787/4cf5b585-en.

[2] S. Danforth, S. Naraian. This new field of inclusive education: beginning a dialogue on conceptual foundations, Intellect. Dev. Disab., Vol. 53, 70-85, 2015, DOI:10.1352/1934-9556-53.1.70

[3] G. Lindsay. Educational psychology and the effectiveness of inclusive education/mainstreaming, Br. J. Educ. Psychol., Vol. 77, 1-24, 2007, DOI: 10.1348/000709906X156881

[4] A.J. Yoro, J.V. Fourie, M. van der Merwe. Learning support strategies for learners with neurodevelopmental disorders: Perspectives of recently qualified teachers, Afr. J. Disabil., Vol.9, 561, 2020, DOI: 10.4102/ajod.v9i0.561

[5] J.M. DeVries, S. Vo $\beta$, M. Gebhardt. Do learners with special education needs really feel included? Evidence from the Perception of Inclusion Questionnaire and Strengths and Difficulties Questionnaire, Res. Dev. Disabil., Vol. 83, 28-36, 2018, DOI: 10.1016/j.ridd.2018.07.007

[6] M. Dey, A.F. Jorm, A.J. Mackinnon. Cross-sectional time trends in psychological and somatic health complaints among adolescents: a structural equation modelling analysis of 'Health Behaviour in School-aged Children' data from Switzerland, Soc. Psychiatry Psychiatr. Epidemiol., Vol. 50, 1189-1198, 2015, DOI: 10.1007/s00127-015-1040-3

[7] E. Hoare, W. Marx, J. Firth, S. McLeod, F. Jacka, G.P. Chrousos, Y. Manios, G. Moschonis. Lifestyle behavioural risk factors and emotional functioning among schoolchildren: The Healthy Growth Study, Eur Psychiatry. Vol. 61, 79-84, 2019, DOI: 10.1016/j.eurpsy.2019.07.002

[8] Tabak, J. Mazur. Social support and family communication as factors protecting adolescents against multiple recurrent health complaints related to school stress, Dev. Period. Med., Vol. 20, 27-39, 2016, ISSN: 1428345X

[9] D. Vondrova, D. Kapsdorfer, L. Argalasova, K. Hirosova, M. Samohyl, L. Sevcikova. The impact of selected environmental, behavioral and psychosocial factors on schoolchildren's somatic and mental health, Rev. Environ. Health., Vol.32, 189-192, 2017, DOI: 10.1515/reveh-2016-0034.

[10] M.M. Bezrukikh. School Children's Health: Problems and Solutions, Siberian Pedagogical Journal., Vol. 9, 11-16 (in Russ.), 2012, eLIBRARY ID: 18486355

[11] Child and Adolescent Health and Development. Disease Control Priorities, 3rd ed., Vol. 8; Bundy, D.A.P., de Silva, N., Horton, S., Jamison, D.T., Patton, J.C. Eds.; Washington, DC: World Bank, 2017, DOI:10.1596/978-1-4648-0423-6 L

[12] S.L. Bach, M.L. Molina, P.L.D. Amaral, A.N. Reyes, K. Jansen, R.A.D. Silva, J.V.D.S. Motta. Emotional and behavioral problems: a school-based study in southern Brazil, Trends Psychiatry Psychother., Vol. 41, 211-217, 2019, DOI: 10.1590/2237-6089-2017-0119.

[13] Caqueo-Urízar, J. Flores, C. Escobar, A. Urzúa, M. Irarrázaval. Psychiatric disorders in children and adolescents in a middle-income Latin American country, BMC Psychiatry, Vol. 20, 104, 2020, DOI: 10.1186/s12888-020-02512-4

[14] F. Mathews, T. Newlove-Delgado, K. Finning, C. Boyle, R. Hayes, P. Johnston, T. Ford. Teachers' concerns about pupils' mental health in a cross-sectional survey of a population sample of British schoolchildren, Child Adolesc. Ment. Health., Vol.26, 99-105. 2021, DOI: 10.1111/camh. 12390

[15] E. Park, M. Kwon. Health-Related Internet Use by Children and Adolescents: Systematic Review, J. Med. Internet. Res., Vol. 20:e120, 2018, DOI: 10.2196/jmir.7731

[16] L. Noskin, V. Pivovarov, S. Landa. Methodology, Hardand Software of Polysystemic Monitoring. In Polysystemic approach to school, sport and environment medicine; Karganov M., Ed.; "OMICS Group Incorporation - eBooks", Foster City, CA, USA., pp. 113-122, 2014, DOI:10.4172/978-1-63278-000-3-001.

[17] R.D. Boehmer. Continuous, real-time, noninvasive monitor of blood pressure: Penaz methodology applied to the finger. J. Clin. Monit., Vol. 3, 282-287, 1987, DOI: 10.1007/BF03337384.

[18] R.M. Bayevsky, G.G. Ivanov. Cardiac Rhythm Variability: the Theoretical Aspects and the Opportunities of Clinical Application, Ultrasound and Functional Diagnostics, Vol. 3, 108-127 (in Russ.), 2003.

[19] J. Gerritsen, B.J. Tenvoorde, J.M. Dekker, P.J. Kostense, L.M. Bouter, R.M. Heethaar. Baroreflex sensitivity in the elderly: influence of age, breathing and spectral methods, Clin, Sci., Vol. 99, 371-381, 2000, DOI: 10.1042/CS19990374

[20] N.B. Pankova, E.N. Arkhipova, I.B. Alchinova, M.Yu. Karganov, A.G. Fesenko, A.D. Fesyun, K.S. Ternovoy, A.A. Abakumov. [Comparative analysis of methods for rapid assessment of the functional state of the cardiovascular system]. Vestnik vosstanovitel'noy meditsiny [Bulletin of Rehabilitation medicine]. Vol. 6, 60-63 (in Russ.), 2011.

[21] Latvala, R. Kuja-Halkola, C. R?ck, B.M. D'Onofrio, T. Jernberg, C. Almqvist, D. Mataix-Cols, H. Larsson, P. Lichtenstein. Association of Resting Heart Rate and Blood Pressure in Late Adolescence with Subsequent Mental Disorders: A Longitudinal Population Study of More Than 1 Million Men in Sweden, JAMA Psychiatry, Vol. 73, 1268-1275, 2016, DOI: 10.1001/jamapsychiatry.2016.2717.

[22] Heart rate variability: standards of measurement, physiological interpretation and clinical use. Task Force of the European Society of Cardiology and the North American Society of Pacing and Electrophysiology. Circulation, Vol. 93, 1043-1065, 1996.

[23] R. Castaldo, L. Montesinos, P. Melillo, C. James, L. Pecchia. Ultra-short term HRV features as surrogates of short term HRV: a case study on mental stress detection in real life, BMC Med. Inform. Decis. Mak., Vol. 19, 12, 2019, DOI: $10.1186 / \mathrm{s} 12911-019-0742-\mathrm{y}$

[24] M. Zhao, L. Guan, Y. Wang. The Association of Autonomic Nervous System Function with Ischemic Stroke, and Treatment Strategies, Front Neurol., Vol. 10, 1411, 2020, DOI: 10.3389/fneur.2019.01411 
[25] N.B. Pankova, I.B. Alchinova, E.V. Afanaseva, M.Yu. Karganov. Functional characteristics of the cardiovascular system in adolescents with high normal blood pressure. Hum. Physiol. (Moscow), Vol. 36, 319-324, 2010, https://doi.org/10.1134/S0362119710030102

[26] T.P. Beauchaine, J.F. Thayer. Heart rate variability as a transdiagnostic biomarker of psychopathology. Int. J. Psychophysiol., Vol. 98, 338-350, 2015, DOI: 10.1016/j.ijpsycho.2015.08.004

[27] C. Koch, M. Wilhelm, S. Salzmann, W. Rief, F. Euteneuer. A meta-analysis of heart rate variability in major depression, Psychol. Med., Vol. 49, 1948-1957, 2019, DOI: $10.1017 /$ S0033291719001351

[28] W. Jung, K.I. Jang, S.H. Lee. Heart and Brain Interaction of Psychiatric Illness: A Review Focused on Heart Rate Variability, Cognitive Function, and Quantitative Electroencephalography, Clin. Psychopharmacol. Neurosci., Vol. 17, 459-474, 2019,DOI:10.9758/cpn.2019. 17.4.459

[29] Y.C. Cheng, Y.C. Huang, W.L. Huang. Heart rate variability in individuals with autism spectrum disorders: A meta-analysis, Neurosci. Biobehav. Rev., Vol. 118, 463-471, 2020, DOI: 10.1016/j.neubiorev.2020.08.007.

[30] A.C. Yang, C-J. Hong, S.J. Tsai. Heart Rate Variability in Psychiatric Disorders. Taiwanese J. Psychiatry [Taipei], Vol. 24, 99-109, 2010.

[31] T. Shinba. Altered autonomic activity and reactivity in depression revealed by heart-rate variability measurement during rest and task conditions, Psychiatry Clin. Neurosci., Vol. 68, 225-233, 2014, DOI: 10.1111/pcn.12123.

[32] H. An, J.W. Han, H.G. Jeong, T.H. Kim, J.J. Lee, S.B. Lee, J.H. Park, K.W. Kim. Parasympathetic predominance is a risk factor for future depression: A prospective cohort study, J. Affect. Disord., Vol. 260, 232-237, 2020, DOI: 10.1016/j.jad.2019.09.015

[33] T. Shinba. Major depressive disorder and generalized anxiety disorder show different autonomic dysregulations revealed by heart-rate variability analysis in first-onset drug-naive patients without comorbidity, Psychiatry Clin. Neurosci., Vol. 71, 135-145, 2017, DOI: 10.1111/pen.12494

[34] B.L. Negrao, P. Bipath, , D. van der Westhuizen, M. Viljoen. Autonomic correlates at rest and during evoked attention in children with attention-deficit/hyperactivity disorder and effects of methylphenidate, Neuropsychobiology, Vol. 63, 82-91, 2011, DOI: $10.1159 / 000317548$

[35] L. Billeci, G. Tartarisco, E. Brunori, G. Crifaci, S. Scardigli, Balocchi, R., Pioggia, G., Maestro, S., Morales, M.A. The role of wearable sensors and wireless technologies for the assessment of heart rate variability in anorexia nervosa. Eat. Weight Disord. 2015, 20, 23-31, DOI: 10.1007/s40519-014-0135-2

[36] T. Ishizawa, K. Yoshiuchi, Y. Takimoto, Y. Yamamoto, A. Akabayashi. Heart rate and blood pressure variability and baroreflex sensitivity in patients with anorexia nervosa, Psychosom. Med., Vol. 70, 695-700, 2008, DOI: 10.1097/PSY.0b013e31817bb090
[37] M. Toichi, Y. Kamio. Paradoxical autonomic response to mental tasks in autism, J. Autism. Dev. Disord., Vol. 33, 417-426, 2003, DOI:10.1023/a:1025062812374

[38] Cevese, G. Gulli, E. Polati, L. Gottin, R. Grasso. Baroreflex and oscillation of heart period at $0.1 \mathrm{~Hz}$ studied by a-blockade and cross-spectral analysis in healthy humans, Am. J. Physiol., Vol. 531, 235-244, 2001, DOI: 10.1111/j.1469-7793.2001.0235j.x

[39] R.W. DeBoer, J.M. Karemaker, J. Strackee. Hemodynamic fluctuations and baroreflex sensitivity in humans: a beat-to-beat model, Am. J. Physiol., Vol. 253, H680 -H689, 1987, DOI: 10.1152/ajpheart.1987.253.3.H680

[40] J.L Hamilton, L.B. Alloy. Atypical reactivity of heart rate variability to stress and depression across development: Systematic review of the literature and directions for future research, Clin. Psychol. Rev., Vol. 50, 67-79, 2016, DOI: 10.1016/j.cpr.2016.09.003

[41] S.M. Zakharov. Variability of arterial pressure at short-term time intervals, Issues of radio electronics, Vol. 1, 72-77 (in Russ.), 2019, https://doi.org/10.21778/2218-5453-2019-172-77

[42] Clamor, J. Sundag, T.M. Lincoln. Specificity of resting-state heart rate variability in psychosis: A comparison with clinical high risk, anxiety, and healthy controls, Schizophr. Res., Vol. 206, 89-95, 2019, DOI:10.1016/j.schres.2018.12.009

[43] G. Perna, A. Riva, A. Defillo, E. Sangiorgio, M. Nobile, D. Caldirola. Heart rate variability: Can it serve as a marker of mental health resilience?: Special Section on "Translational and Neuroscience Studies in Affective Disorders". J. Affect. Disord., Vol. 263, 54-761, 2020, DOI: 10.1016/j.jad.2019.10.017

[44] G. R. Sandercock, P. D. Bromley, D. A. Brodie. The reliability of short-term measurements of heart rate variability, International journal of cardiology, Vol. 103, 238-247, 2005, doi: 10.1016/j.ijcard.2004.09.013.

[45] R. Castaldo, L. Montesinos, P. Melillo, S. Massaro, L. Pecchia. To What Extent Can We Shorten HRV Analysis in Wearable Sensing? A Case Study on Mental Stress Detection. In: Eskola H., Väisänen O., Viik J., Hyttinen J. (eds) EMBEC \& NBC 2017. EMBEC 2017, NBC 2017. IFMBE Proceedings, Vol. 65, Springer, Singapore. (2018) https://doi.org/10.1007/978-981-10-5122-7_161

[46] S. Massaro, L. Pecchia. Heart Rate Variability (HRV) Analysis: A Methodology for Organizational Neuroscience, Organizational Research Methods, Vol. 22, 354-393 2019. https://doi.org/10.1177/1094428116681072

[47] P. Mavrenkova, N. Pankova, M. Lebedeva, M. Karganov. Features of psychomotor coordination in adolescents with neuropsychiatric pathology enrolled in a standard educational program, Int. J. Psychophysiol. -- Vol. 168, Supplement. - P. S160. 2021, https://doi.org/10.1016/j.ijps ycho.2021.07.448

[48] Huaibo Xin, "Addressing Mental Health Stigmas among Refugees: A Narrative Review from a Socio-Ecological Perspective," Universal Journal of Public Health, Vol. 8, No. 2, pp. 57 - 64, 2020. DOI: 10.13189/ujph.2020.080202. 